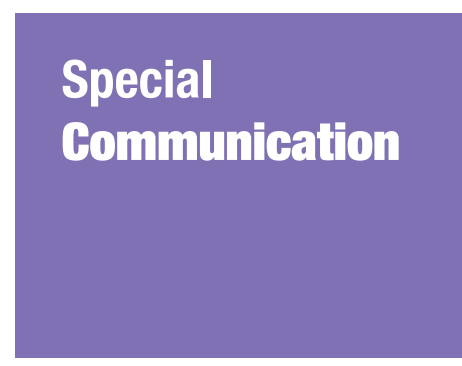

Submitted: 13 Feb 2017

Accepted: 11 Aug 2017

Online: 26 Oct 2017

\section{Provision of Prosthetic Services Following Lower Limb Amputation in Malaysia}

\author{
Nooranida Arifin ${ }^{1}$, Hasif Rafidee HaSBollah ${ }^{2}$, Muhammad Hafiz \\ HanAFi $^{3,4}$, Al Hafiz lbrahim ${ }^{5}$, Wan Afezah Wan Abdul Rahman ${ }^{6}$, \\ Roslizawati CHe AzIz ${ }^{2}$
}

$1 \quad$ Department of Biomedical Engineering, Faculty of Engineering University of Malaya, Kuala Lumpur

$2 \quad$ Faculty of Hospitality, Tourism, and Wellness, University Malaysia Kelantan, City Campus, Pengkalan Chepa, Kelantan

3 Department of Neuroscience, School of Medical Sciences, Universiti Sains Malaysia, 16150 Kubang Kerian, Kelantan

4 Center for Neuroscience Services and Research, Universiti Sains Malaysia Health Campus, 16150 Kubang Kerian, Kelantan

5 Orthopedic Department, Universiti Sains Malaysia Hospital, Kelantan

$6 \quad$ School of Distance Education, Universiti Sains Malaysia, Penang

To cite this article: Arifin N, Hasbollah HR, Hanafi MH, Ibrahim AH, Wan Abdul Rahman WA, Che Aziz R. Provision of prosthetic services following lower limb amputation in Malaysia. Malays J Med Sci. 2017;24(5):106-111. https:// doi.org/10.21315/mjms2017.24.5.12

To link to this article: https://doi.org/10.21315/mjms2017.24.5.12

Keywords: amputation, supply, lower limb, prosthesis

\section{Introduction}

According to International Classification of Functioning, Disability and Health (ICF), lower limb amputation is a form of physical disability which impairs body structures and results in activity limitation and participation restriction (1). Limb loss resulting from acquired amputation is often due to disease, injury or surgery, whereas congenital limb loss is present at birth $(2,3)$. Lower limb amputations account for $84 \%$ of total amputations, while upper limb amputation account for only $16 \%$ (4). Amputations of the lower extremities often result from vascular-related diseases (with or without diabetes) and account for $80 \%-90 \%$ 
of all amputations in Western countries (5). A person with diabetes has a $10-30$ times greater risk of undergoing lower limb amputation than the general population (6). It is estimated that around $20 \%-50 \%$ of diabetes amputees will require a second leg amputation within one to three years, and more than $50 \%$ of amputees will need another amputation within five years (7).

Amputation not only affects a person physically and psychologically, but also presents a major challenge for the nation $(2,8)$. Amputations contribute significantly to the increasing cost of healthcare systems globally, with the annual cost of lower extremity amputations in the United States reaching USD4.3 billion (5). Following amputations, one of the rehabilitation goals is to restore the daily living activities of amputees by reducing their dependency on others and increasing their mobility. Hence, a person with lower limb amputation will be prescribed a prosthesis to regain mobility. A prosthesis is defined as an "externally applied device consisting of a single component or an assembly of components used to replace wholly, or in part, an absent or deficient lower or upper-limb segment' (9). In general, there are four types of prostheses: transradial and transhumeral prostheses to replace a missing arm below the elbow and above the elbow, respectively; and transtibial and transfemoral prostheses to replace a missing leg below the knee and above the knee, respectively. Technically, common prosthetic components include but are not limited to a socket, interface systems, joints, terminal devices and a foot. Amputees must be prescribed with the correct prosthesis components according to such factors as the amputation level, the amputation aetiology and the amputee's activities in daily life. Provision of high-quality prosthetic services is crucial to ensure the independence and social integration of amputees.

\section{Amputation Prevalence in Malaysia}

According to WHO (10), $0.5 \%$ of the population of a developing country have a disability that will require a prosthesis or orthosis and related rehabilitation services. This prediction suggests that around 160,000 of Malaysia's current population of 32 million (11) need prosthetic or orthotic devices. The population is projected to reach 38.5 million by 2040 (11), including approximately 200,000 individuals with a physical disability.

A previous National Health and Morbidity Survey (NHMS) reported that the prevalence of diabetes mellitus among Malaysians increased from $6.3 \%$ in 1986 to $8.2 \%$ in 1996 (12). Surprisingly, as noted in the NHMS III report (13), by 2006 this had increased to $17.5 \%$. This significantly exceeded the prediction which estimated that by 2025, the prevalence of diabetes mellitus in Malaysia would be only $11 \%-14 \%$ (14). The trend of increasing diabetes prevalence in this country seems to continue; the most recent study revealed a prevalence of 22.6\%, almost double that reported in 2006 (15). Despite proactive efforts by the Ministry of Health, such as the establishment of Diabetes Resource Centres in hospitals and a national steering committee for improving the screening and management of diabetes in clinics, the national prevalence of diabetes is expected to rise to around $22 \%$ in $2020(12,13)$.

This alarming trend may be associated with an increase in the prevalence of obesity and overweight in Malaysia (16). Scientific study has shown that diabetes mellitus is a key risk factor leading to lower limb amputation (17) such that in 2005, the loss of a lower limb due to diabetes was estimated to occur every 30 seconds somewhere in the world (14). The diabetes epidemic remains a serious threat and burden to Malaysia and has the potential to increase the number of physically-disabled persons in the country.

\section{Provision of Prosthetic Services in Malaysia}

In 2006, the General Assembly of the United Nations adopted the Convention on the Rights of Persons with Disabilities, Article 25 of which states that persons with disabilities have the right to receive the highest possible standard of health without discrimination on the basis of disability (18). Applying this to the amputee population, the provision of affordable and high-quality prosthetic services can be seen as a human rights issue, one that the government must take seriously.

However, in today's world, the World Health Organisation estimates that only $5 \%-$ $15 \%$ of persons with disabilities have access to assistive technology, especially in low- and middle-income countries (19). Provision of highquality prosthetic services not only ensures the comfort and fit of a prosthesis but also helps to elevate the confidence and safety of the user (19). A functioning prosthesis will improve the user's quality of life, satisfaction, educational and job opportunities and social acceptance. 
Historically, the provision of prosthetic services in Malaysia began in 1937 when the British established an orthopaedic appliance workshop in the National Leprosy Control Center in Sungai Buloh (20). In 1967, a centre for orthotics and prosthetic services was established in the University Hospital (now known as the University of Malaya Medical Centre). Two years later, the National Limb Fitting Centre was under the administration of the General Hospital Kuala Lumpur with three technicians and one rehabilitation physician who were specially trained in orthotic and prosthetic technology (20). In order to provide optimum access to prosthetic services throughout the nation, it is suggested that services should be developed at the national, state and district levels (10).

In 1998, the Asian Prosthetics and Orthotics Workshop was held in Japan. This was organised by the International Society of Prosthetics and Orthotics (ISPO) and the Japanese Society for Prosthetics and Orthotics so that key ISPO persons from South-East Asia and experts from ISPO could exchange knowledge and experience. With the aim of developing a unified approach in Asia to achieve the best prosthetic and orthotic care in the 21st century, several critical actions must be prioritised to benefit the amputees in Malaysia. These include increasing the efficiency and quality of prosthetic services, facilitating education and training in prosthetic technology and creating easy access to prosthetic services (20). Prosthetic services were mainly provided by the government hospitals in its early inception, until in the 1970 s and present when the blooming of private prosthetic companies has changed the prosthetic services scenario. The emergence of private services is due to a government policy decision to outsource all medical implant services, including prostheses, to the private sector. However, in the absence of a governance body for these purposes, there is lack of price and quality control for prosthetic devices.

\section{Financial Cost of Prosthesis}

The increasing demand for a better quality of life for individuals with missing limbs impacts the market positively on governing the global prosthetic business. This has caused tremendous technological advancement in prosthetic componentry (such as prosthetic feet, knee joints, adapters and liners) according to the specific amputation type. In Malaysia, the cost of a prosthesis typically varies between RM4000-RM15000 and is higher if advanced components or computerized systems are used. Unfortunately, most of the certified prosthetists and orthotists (CPOs) are based in West Malaysia and can provide optimal services only in this region. Some of them try to cover other parts of Malaysia, but although the quality of the prostheses is good, their price is increased by the cost of transportation and other expenses. A few self-taught, uncertified prosthetic makers in East Malaysia try to fill this gap, but the quality of their prosthetic devices is lower than that of companies employing CPOs. The high price of prostheses imposes a financial burden on a significant percentage of amputees in Malaysia. Consequently, many of them are left with the choice of lower-priced prosthetics that are less effective and inhibit their rehabilitation progress.

The cost of prostheses is a major issue, especially in East Peninsular and East Malaysia. No proper data about how people pay for prosthetic services are collected. From the authors' experience, this can range from selfpaying patients, assistance from the employer or insurance company (the Public Services Department for civil servants, the Ministry of Health - under Tabung Bantuan Perubatan, the Welfare Department, Social Security Organisation SOCSO, Political Fund, Company's insurance, Religion-related association, NGOs) and by government agencies (Welfare department, Health Ministry, Universities under Ministry of Higher Education). Moreover, government hospitals treat prostheses in the same way as other medical implants, and these are not covered by the annual hospital budget. Thus, patients need to find resources to finance their prosthesis. The lack of structured prosthetic service management system leads to reimbursement issues which increase the waiting period for amputees to be fitted with a prosthesis. These constraints are likely to remain as major obstacles to improving the nation's prosthetic service unless there are substantial changes in government policies to achieve mutual concordance concerning prosthetic services.

One option that could reduce the overall cost of prostheses could be central fabrication and mass production. By outsourcing the production process, prosthetists could maximise clinical productivity and consequently provide excellent patient care to amputees. In addition, private companies could reduce their operating costs by eliminating the need for large working areas, specialised machinery and additional technical staff. It has been shown that mass- 
produced, pre-fabricated orthotic and prosthetic devices have comparable fit and function to custom-made devices. Private practice and government hospitals could work in partnership to develop a cost effective model based on central fabrication and a mass production approach. However, in certain specific deformity cases, a custom-made device will always be required for effective and successful treatment outcomes.

\section{Current Amputation Statistics in Malaysia}

It is estimated that around 160,000 individuals need prosthetic or orthotic devices in Malaysia (10). However, published data on the current number of individuals with a lower limb amputation who need a prosthetic device or prosthetic services in this country are scarce. The only amputation data available are from the National Orthopaedic Registry Malaysia Diabetic Foot 2009, which reported 19 cases of upper and 405 cases of lower limb amputations due to infections (21). These data only represent amputation records based on diabetes-related infections for a single year. Data on the number of amputees that gives information about the cause and level of amputation and the age, gender and activity level of amputees is not collected in Malaysia. Amputation records showing statistics and trends would help rehabilitation teams to provide pragmatic services to accommodate the needs of persons with a lower limb amputation. At the national level, statistical records would be very useful for policy makers, the prosthetic industry, prosthetic service providers and researchers; they would measure the success or otherwise of the government's efforts to reduce the incidence of lower limb amputation and suggest the actions necessary to enhance the quality of prosthetic devices and services.

\section{Prosthetic Workforce in Malaysia}

Prosthetic services were initially delivered by untrained artisans until, in 1970s and 1980 , they were given proper education and training in orthotic and prosthetic technology by professionals from the United Kingdom, Australia, Hong Kong, Japan and Germany. This training was supported by Malaysia's Department of Welfare and Ministry of Defence, among other funding bodies.

The responsibility for providing exemplary prosthetic services lies with the personnel providing those services. It is important that these personnel have an adequate level of education and training. According to $\mathrm{WHO}$ and ISPO guidelines (20), three categories of personnel are involved in prosthesis fabrication: prosthetists/orthotists (Category I, degree entry); orthopaedic technologists (Category II, diploma entry); and orthopaedic technicians/ bench workers (Category III, certificate entry). To date, the University of Malaya is the only higher education provider producing degreelevel prosthetics and orthotics graduates to serve the demands of local prosthesis users. However, this degree program is yet to be accredited by ISPO as a Category 1 education program.

The adequacy of the prosthetic workforce is paramount to meet the demand for highquality prosthetic services. However, there is no benchmark for measuring the shortage or oversupply of prosthetists and orthotists. Recently, the National Commission on Orthotic and Prosthetic Education (NCOPE) reported that the demand-to-supply ratio in orthotic and prosthetic services in the United States is estimated at 1.3 and is expected to increase to 1.6 by 2025 to meet the growing demand (22). According to ISPO, the average number of patients that can be served by a prosthetist, orthotist or technician is 250 patients per year (10). This estimate suggests that a workforce of 640 is currently needed in Malaysia to provide prosthetic and orthotic services to disabled individuals. While the nation has a database for the number of personnel related to prosthetic services, such as physiotherapists and occupational therapists (23), statistics for prosthetists are yet to be reported. To determine the human resource needed for prosthetic services, information such as the range of prosthetic services and number of amputees requiring a prosthesis must be compiled.

\section{Conclusion}

Disability caused by physical impairment following lower limb amputation accentuates the importance of providing high-quality prosthetic services to the community. Policy makers and the leaders of health and social care providers should facilitate access to appropriate prosthetic technology. The outcomes of this proposed study will serve as a catalyst to create linkages between ministries such as the Ministry of Health and Ministry of Woman, Family and Community Development (Department Social Welfare), 
NGOs and industry sectors as the major steering forces in the provision of prosthetic services. Most importantly, prosthetic users will be the primary beneficiaries of efforts to create excellent prosthetic services in this country. As Malaysia enters the new millennium, the amputee population must be equipped with prosthetic technology that provides functional and economic independence and allows them to contribute to the nation's aspiration of National Transformation 2050 (TN50).

\section{Acknowledgements}

The authors are grateful to University Malaysia Kelantan for the financial support from Geran Keserakanan UMK-USM (R/MYRA/ A11.00/01226A/003/2017/000409).

\section{Conflict of Interest}

The authors have no conflict of interest.

\section{Authors' Contributions}

Conception and design: NA

Drafting of the article: NA

Critical revision of the article for important intellectual content: $\mathrm{HRH}, \mathrm{MHH}, \mathrm{AHI}$, WAWAR, RCA

Final approval of the article: HRH, MHH, AHI, WAWAR, RCA

Obtaining of funding: HRH

\section{Correspondence}

Dr Nooranida Arifin

$\mathrm{PhD}$ (University of Malaya)

Department of Biomedical Engineering,

Faculty of Engineering, University of Malaya,

50603 Kuala Lumpur, Malaysia

Tel: $(+603) 79677693$

Fax: (+603) 79674579

E-mail: anidaum@um.edu.my

\section{References}

1. World Health Organization. World report on disability. Geneva; 2011.

2. Nielsen CC. Etiology of amputation. In: Lusardi MM, Nielsen CC, editors. Orthotics and prosthetics in rehabilitation. 2nd ed. St. Louis, Missouri: Saunders Elsevier; 2007.

3. Smith DG. General principles of amputation surgery. In: Smith DG, Michael JW, Bowker JH, editors. Atlas of amputation and limb deficiency: Surgical, prosthetic and rehabilitation principles. 3rd ed. Rosemont, IL: American Academy of Orthopaedic Surgeons; 2004.

4. World Health Organization. The rehabilitation of people with amputations. Geneva; 2004.

5. Dillingham TR, Pezzin LE, MacKenzie EJ. Limb amputation and limb deficiency: epidemiology and recent trends in the United States. Southern Med J. 2002;95(8):875-883. https://doi. org/10.1097/00007611-200295080-00019

6. Vamos EP, Bottle A, Edmonds ME, Valabhji J, Majeed A, Millett C. Changes in the incidence of lower extremity amputations in individuals with and without diabetes in England between 2004 and 2008. Diabetes Care. 2010;33(12):25922597. https://dx.doi.org/10.2337/dc10-0989

7. Van Gils CC, Wheeler LA, Mellstrom M, Brinton EA, Mason S, Wheeler CG. Amputation prevention by vascular surgery and podiatry collaboration in high-risk diabetic and nondiabetic patients, The Operation Desert Foot experience. Diabetes Care. 1999;22(5):678-683. https://doi.org/10.2337/diacare.22.5.678

8. Gitter A, Bosker G. Upper and lower extremity prosthetics. 4th ed. Philadelphia: LippincottRaven; 2005.

9. International Standard Organization. ISO 85491: Prosthetics and orthotics - Vocabulary Part 1: General terms for external limb prostheses and external orthoses. Geneva; 1989. 
10. World Health Organization. Guidelines for training personnel in developing countries for prosthetics and orthotics services. Geneva; 2005.

11. Malaysia Statistics Department. Population clock. (cited 2017 February 12). Available from https:// www.statistics.gov.my

12. Mafauzy M. Diabetes mellitus in Malaysia. Med $J$ Malaysia. 2006;61(4):397-398.

13. Institute for Public Health, Ministry of Health. National health morbidity survey 2015. Noncommunicable diseases, risk factors and other health problems. Vol. II. Malaysia: Institute for Public Health, Ministry of Health, Kuala Lumpur, 2015 .

14. Karel B, Ali F, William VH, Riley P. Time to act. The Netherlands: International Diabetes Federation and International Working Group of the Diabetic Foot; 2005.

15. Wan Nazaimoon WM, Md Isa SH, Wan Mohamad WB, Khir AS, Kamaruddin NA, Kamarul IM, et al. Prevalence of diabetes in Malaysia and usefulness of HbA1c as a diagnostic criterion. Diabet Med. 2013;30(7):825-828. https://doi.org/10.1111/ dme.12161

16. Wan Mohamud WN, Musa KI, Md Khir AS, Ismail AAS, Ismail IS, Kadir KA, et al. Prevalence of overweight and obesity among adult Malaysians: an update. Asia Pac J Clin Nutr. 2011;20(1):3540.
17. Resnick HE, Valsania P, Phillips CL. Diabetes mellitus and nontraumatic lower extremity amputation in black and white Americans: the national health and nutrition examination survey epidemiologic follow-up study, 1971-1992. Arch Intern Med. 1999;159(20):2470-2475. https:// doi.org/10.1001/archinte.159.20.2470

18. United Nation. Convention on the Rights of Persons with Disabilities; 2006 [cited 2016 October 8]. Available from from: http://www.undocuments.net/a61r106.htm

19. World Health Organization. Standards for prosthetics and orthotics service provision: 20152017 work plan. Geneva; 2015.

20. Omar Z: Orthotics \& prosthetics: local technology and social service in Malaysia. ISPO An Asian Prosthetics and Orthotics Workshop Japan Final Report, 1998.

21. National Orthopaedic Registry Malaysia. Annual report of National Orthopaedic Registry Malaysia (NORM) diabetic foot 2009. Malaysia; 2010.

22. DaVanzo JE, El-Gamil A, Heath S, Pal S, Li J, Luu P, Dobson A. Projecting the adequacy of workforce supply to meet patient demand analysis of the Orthotics and Prosthetics (O\&P) profession. USA; 2015.

23. Ministry of Health Malaysia. Health indicators 2014. Malaysia; 2014. Report Number: ISSN 1511$4589 \mathrm{MOH} / \mathrm{S} / \mathrm{RAN} / 74.14(\mathrm{TR})$ 